La sangre, la furia y la memoria: Ramona Parra en el martirologio comunista de la postguerra (Chile 1946-1947)

Viviana Bravo Vargas

páginas / año 9 - n 20 Mayo- Agosto / ISSN 1851-992X/ pp. 32-52 / 2017

http://revistapaginas.unr.edu.ar/index.php/RevPaginas

\title{
La sangre, la furia y la memoria: Ramona Parra en el martirologio comunista de la postguerra (Chile 1946-1947) ${ }^{1}$
}

\author{
Blood, fury and memory: Ramona Parra in the communist \\ martyrology of the postwar period (Chile 1946-1947)
}

\author{
Viviana Bravo Vargas \\ Universidad Academia de Humanismo Cristiano, Chile \\ vivianabravo@gmail.com
}

\begin{abstract}
Resumen
Este artículo explora los sentidos ideológicos-políticos con que el Partido Comunista de Chile interpretó la masacre de la Plaza Bulnes y la muerte de Ramona Parra ocurrida el 28 de enero de 1946. Postulando que interiorizarse en la ceremonialización de la muerte, a través de la identificación y reconstrucción de hechos considerados claves, como los homenajes y rituales fúnebres; las campañas de reclutamiento; y la movilización por la elección presidencial y defensa del programa durante el gobierno de Gabriel González Videla, permite comprender los desafíos, relaciones y tensiones que enfrentaba el partido durante el gobierno interino de Alfredo Duhalde y la primera etapa de la administración de González Videla. Para este fin se utilizan principalmente documentos partidarios, el sumario por el suceso de la Plaza Bulnes y publicaciones periódicas de la época.
\end{abstract}

\section{Palabras Clave}

Masacre obrera; Ramona Parra; Martirologio; Postguerra; Comunistas; Chile

\begin{abstract}
The following paper aims at exploring the ideological and political sense of how the Chilean Communist Party has interpreted the historical event known as The Massacre of Bulnes Square and the resulting death of Ramona Parra, a party leader, on January 28th 1946. We state that facts such as getting acquainted with the aftermath through the process of identifying and reconstructing key historical facts, such as tributes, mourning rituals of the
\end{abstract}

${ }^{1}$ Este artículo es parte del proyecto de postdoctorado FONDECYT N${ }^{\circ} 3160354$, titulado "Lucha de calles: voces y trayectorias de la protesta popular en Santiago de Chile, 1946-1969"

Esta obra está sujeta a la Licencia Reconocimiento-NoComercial-CompartirIgual 4.0 Internacional de Creative Commons. http://creativecommons.org/licenses/by-nc-sa/4.0/

(c) EY-NC-SA 


\section{Viviana Bravo Vargas}

time, enrolling campaigns and the drive to the presidential election and defense of the governmental program during Gabriel Gonzàlez Videla lead to an understanding of the challenges, relations and tensions faced by the Communist Party during the interim government of Alfredo Duhalde and the period ruled by Gonzalez Videla. For collecting information on the aforementioned historical facts, we used documents issued by the Communist Party in Chile, the records of the trial on the issues of Bulnes Square and also by reviewing journalistic material of the time.

\section{Keywords}

Massacre; Ramona Parra; Martyrology; Postwar; Communists; Chile

El 28 de febrero de 1946, mientras participaban en una manifestación autorizada en el centro de la ciudad de Santiago, más de 50 obreros fueron heridos de bala y seis resultaron muertos, entre ellos Ramona Parra militante de las Juventudes Comunistas (JJCC). El hecho que fue conocido como la masacre de la Plaza Bulnes impactó profundamente en la opinión pública de la época, y gatilló una crisis política que propició entre otras cosas, el exitoso Paro Nacional del 30 de enero.

A un año de los sucesos, Cesar Godoy Urrutia, entonces diputado del Partido Comunista de Chile (PCCH) escribía: "En lo que todos tendrán que coincidir es que el 28 de enero de 1946 constituye una fecha incorporada al martirologio de nuestro pueblo, desde cuyo día, negros y pesados nubarrones cubrieron el cielo de nuestra patria". Su texto se titulaba "La historia se escribe con sangre"2. Conmovidos por la muerte, Pablo Neruda y Violeta Parra, escritores de la Generación Literaria del 38 y ciudadanos desconocidos, dedicaron textos y poemas; le cantaron, pintaron, inmortalizaron. Fue una fecha y un nombre que trascendería a través de diversas generaciones que los convirtieron en una bandera de lucha.

¿Pero cómo fue experimentada y significada la masacre y la muerte de Ramona por el PCCH? ¿cómo operó la construcción de un sentido orgánico y político asociado a esta muerte? ¿Qué memoria colectiva afloró en el momento político en que se situaban los militantes comunistas, al calor de las relaciones sociales que se confrontaban dentro del campo de batalla hegemónico? Consideramos que las respuestas a estas preguntas nos pueden dar indicios sobre los desafíos, relaciones $y$ tensiones que enfrentaba el partido en el contexto de la postguerra, del que sabemos realmente poco. En efecto, llama la atención que los estudios sobre el comunismo chileno se concentren principalmente en las primeras décadas del siglo $\mathrm{XX}$ y que posteriormente salten en cuantioso caudal hacia la comprensión del período que cubre el proceso de la Unidad Popular hasta la actualidad ${ }^{3}$. De esta

\footnotetext{
2 El Siglo, Santiago, 28/01/1947, p 5

${ }^{3}$ Sobre los primeros años del PCCH, Hernán Ramírez, Origen y formación del Partido Comunista de Chile, Santiago, Progreso, 1984; Sergio Grez, Historia del comunismo en Chile. Los tiempos de Recabarren (1912-1924), Santiago, LOM, 2011 y Julio Pinto, Luis Emilio Recabarren. Un biografía histórica, Santiago, LOM, 2013. Respecto a la historia reciente del PC, Viviana Bravo, Con la razón y la fuerza venceremos! la rebelión popular y la subjetividad comunista en los '80, Santiago, Ariadna, 2010;
} 


\section{La sangre, la furia y la memoria: Ramona Parra en el martirologio comunista de la postguerra (Chile 1946-1947)}

manera, la década de 1940 ha quedado relativamente descuidada, a excepción de trabajos -aunque escasos- fundamentales. Uno de ellos es el realizado por Andrew Barnard, que se concentra en reconstruir detalladamente la historia partidaria desde el aporte del partido a los procesos de democratización nacional desarrollados en el camino institucional ${ }^{4}$. Otro aporte a destacar es el de Jody Pavilack, quien analiza desde la perspectiva de la historia local el conflicto de los mineros del carbón en la zona sur del país. ${ }^{5}$

Desde la ciencia política resulta importante el texto de Carlos Huneeus sobre "La Guerra Fría en Chile", donde transparenta los dispositivos jurídicos normativos que durante el gobierno de Gabriel González Videla afectaron a los comunistas y sus consecuencias en el sistema político chileno ${ }^{6}$. En específico sobre la matanza de la Plaza Bulnes se han desarrollado dos artículos desde la composición social de la protesta y el encadenamiento de luchas obreras que experimentó el período. Además de una tesis sobre el conflicto comunista-socialista manifiesta en el área sindical. ${ }^{7}$

A partir de esta constatación, el presente trabajo busca aportar al conocimiento del periodo en general y del PCCH en particular, desde los sentidos ideológicos-políticos con que se experimenta la muerte y elabora simbólicamente el martirologio partidario. Planteamos que seguir los espacios y formas de la rememoración nos puede aportar importantes luces para identificar no solo las estructuras de sentimiento que propuso Raymond Williams ${ }^{8}$, para acentuar los significados y valores tal como son vividos y sentidos activamente, sino que además identificar las formas y discursos movilizadores que ideó el PCCH en aras de fortalecer la organización y enfrentar un complejo momento político, marcado por las políticas antiobreras del gobierno interino de Alfredo Duhalde y la primera etapa de la administración de González Videla.

"El sufrimiento en común une más que el gozo (...) los duelos valen más que los triunfos; porque imponen deberes; piden el esfuerzo en común”, escribió Ernest Renan en 1882, interesado en encontrar los hilos subjetivos que conforman el tejido

\footnotetext{
Luis Rojas, De la rebelión popular a la sublevación imaginada, Santiago, LOM, 2011; Rolando Álvarez, Arriba los pobres del mundo, Santiago, LOM, 2011

${ }^{4}$ Andrew Barnard, The Chilean Communist Party: 1922-1947. Ph.D thesis, University of London, 1977

5 Jody Pavilack, Mining for the Nation. The Politics of Chile's Coal Communities from the Popular front to the Cold War. University Park: The Pennsylvania State University Press, 2011.

6 Carlos Huneuus, La Guerra Fría Chilena. Gabriel González Videla y La Ley Maldita. Santiago, Debate, 2009

${ }^{7}$ Alfonso Salgado, "La familia de Ramona Parra en la Plaza Bulnes: Una aproximación de género a la militancia política, la protesta social y la violencia estatal en el Chile del siglo". Izquierdas $\mathrm{N}^{\circ} 18$, Santiago de Chile, abril 2014, pp. 128-145; Viviana Bravo Vargas, "Chile no va hoy a la fábrica: Protesta obrera y represión política en el verano de 1946”, Izquierdas №35, Santiago de Chile, septiembre 2017, pp. 199-232 y Cristian Pozo Mayorga, Ocaso de la unidad obrera en Chile: confrontación comunista-socialista y la división de la CTCH (1946-1947). Tesis de Magíster., Santiago, Universidad de Chile, 2013.

${ }^{8}$ Raymond Williams, Marxismo y literatura. Las Cuarenta, Buenos Aires, 2009, p 180.
} 


\section{Viviana Bravo Vargas}

nacional. ${ }^{9}$ Y si el estado-nación rememora sus héroes nombrando calles, irguiendo monumentos, la memoria subalterna también pondrá marcas en su memoria histórica a través de ritos y rituales para honrar a los caídos e inscribirlos en el tiempo largo de las luchas sociales. Como ha planteado Ricardo Melgar para el caso latinoamericano, la muerte del luchador comunista o proletario se asocia dentro del colectivo con un valor de alta densidad política y simbólica en tanto incorpora elementos inherentes de la cultura política popular resultando un proceso de ceremonialización de la muerte con fuerte contenido subjetivo para la experiencia militante. En dicho proceso se exalta un patrón de simbolización vinculado a la cultura de la guerra, con un claro eslabonamiento entre el sacrifico y el renacer, en que la muerte queda resituada en su dimensión sacrificial como posibilidad y como deber cargado de positividad. ${ }^{10}$

A partir de esta reflexión, la hipótesis de este trabajo postula que en el caso de la matanza de la Plaza Bulnes la ceremonialización del martirologio que elabora el PCCH recorre tres operaciones bastante nítidas: la inscripción de la matanza en una tradición de lucha, muerte y sacrificio (continuidad histórica); la encarnación de atributos militantes en la figura de Ramona Parra que son los que reivindica, requiere y fomenta el PCCH y que la levantan a la categoría de heroína (emblema de lucha); y por último, el desarrollo de un proceso de "renacimiento en el colectivo" que impone desafíos y tareas concretas a corto y mediano plazo (dimensión proyectual). Por tanto, utilizando principalmente documentos partidarios, el sumario por los sucesos de la Plaza Bulnes y publicaciones periódicas de la época, los objetivos de este artículo se concentrarán en rastrear y reconstruir dichas dinámicas en los homenajes y rituales fúnebres; las campañas de reclutamiento; y la movilización por la elección presidencial y defensa del programa que encabezó el PCCH durante el gobierno de González Videla.

\section{Morir de pie}

El comicio de la Plaza Bulnes de Santiago había sido convocado por la Confederación de Trabajadores de Chile (CTCH), para expresar su solidaridad con los sindicatos de las oficinas salitreras de Humberstone y Mapocho, que al calor de una huelga contra los abusos patronales eran sancionados con la supresión de la personalidad jurídica, en un contexto de importante agitación obrera. Atendiendo el llamado, desde las seis de la tarde arribaron las delegaciones de trabajadores, pero

\footnotetext{
${ }^{9}$ Ernest Renan, “¿Qué es una Nación?”, Conferencia dictada en la Sorbona, París, 11 de marzo de 1982. Disponible en:

http://enp4.unam.mx/amc/libro_munioz_cota/libro/cap4/lec01_renanqueesunanacion.pdf,

[Consulta: 03/06/2017].

${ }^{10}$ Ricardo Melgar Bao, "Una cultura política en formación: los cominternistas centroamericanos”. En: Elvira Concheiro, Massimo Modonesi, Horacio Crespo (coord), El comunismo: otras miradas desde América Latina, México, CEIICH-UNAM, 2007 y “Muerte, martirologio y mitología del renacer en las guerrillas latinoamericanas". En: La memoria sumergida, 2002. Disponible en: http://www.cedema.org/uploads/La\%20memoria\%20sumergida.pdf, [Consulta: 03/06/2017].
} 


\section{La sangre, la furia y la memoria: Ramona Parra en el martirologio comunista de la postguerra (Chile 1946-1947)}

el asombro fue inmediato ante la nutrida disposición de fuerza policial compuesta por 250 carabineros, un número inusual para esta clase de eventos, que solía fluir entre 70 y 90 efectivos como máximo ${ }^{11}$. Si esto ya podía considerarse una provocación, las disposiciones de la tropa caldearon más los ánimos, como rodear el escenario o abrir, ensanchar y resguardar un inexplicable espacio circular en medio de los manifestantes. ${ }^{12}$ Pronto comenzaron las fricciones. Golpes con armas de servicio de un lado, empujones, chiflidos, lanzamiento de pasto, palos y hasta maceteros por el otro.

Entonces una ráfaga de disparos se extendió durante varios minutos. Los asistentes se refugiaron en edificios y calles aledañas, algunos se tiraron al suelo, mientras otros eran alcanzados por las balas. Se contabilizaron más de 80 heridos, 50 de ellos con impactos de bala y seis muertos: Filomeno Chávez, César René Tapia, Manuel López, Adolfo Lisboa, Alejandro Gutiérrez y Ramona Parra.

La represión a un comicio autorizado y de carácter pacífico gatilló una conmoción pública y crisis política en el país. El Ministro de Obras Públicas, Eduardo Frei renunció a su cargo, y fue reemplazo por el general Manuel Tovarías Arroyo Por su parte, el gobierno de Alfredo Duhalde nombró como Ministro del Interior al almirante Vicente Merino Bielich. Entre sus primeras medidas declaró el Estado de Sitio, se realizaron arrestos, se dio orden de impedir la difusión de los sucesos y allanó varios diarios, entre ellos El Siglo, órgano difusor del PCCH. Como respuesta inmediata la CTCH reforzó la idea del paro nacional para el 30 de enero enmarcado en los funerales de las víctimas.

“Cobarde masacre" titulaba El Siglo el día después de la tragedia. Más abajo presentaba fotografías de los cadáveres de Ramona y René Tapia. Si bien esto no era una licencia de El Siglo ya que en la época era cotidiano observar cadáveres en la prensa es importante considerar el efecto que tenían las imágenes cuando la televisión no era un medio masivo. La amplia cobertura del suceso hacía eco de la indignación:

Ramona Parra joven obrera de Recalcine, perdió la voz, la vida, cuando alzando el puño, gritaba su solidaridad con los obreros del Norte y su protesta contra los gobernantes elegidos por ellos mismos, que ahora han manchado de ignominia sus hojas de servicio ciudadano... ha pasado a engrosar la lista incontable de los héroes que rindieron y seguirán rindiendo sus vidas para la construcción de un Chile mejor y libre de carroña reaccionaria y sanguinaria". ${ }^{13}$

Ya en esta primera entrega es notoria la reivindicación combativa, heroica, parte de una tradición de lucha. Aunque la muchacha estaba desarmada y el evento era pacífico ella no era un sujeto pasivo que simplemente recibía la agresión de sus

\footnotetext{
11 Sumario por sucesos ocurridos en la Plaza Bulnes, Causa rol № 80-1946, Segundo Juzgado Militar de Santiago, f 306

12 Una reconstrucción de los hechos en Viviana Bravo, "Chile no va hoy....", Op Cit

${ }^{13}$ El Siglo, Santiago, 29/01/ 1946, portada
} 


\section{Viviana Bravo Vargas}

asesinos, sino que estaba apoyando una lucha obrera de la que se sentía parte. Pero aún más, el proceso de revestimiento como combatiente ejemplar llevará a integrar en el imaginario la forma en que Ramona enfrentó a la muerte. Se insistirá en que murió de pie, increpando a los masacradores del pueblo. Continúa El Siglo: "En la plaza la vieron. Vibraba ante los disparos rozando las calles y cuando volvió el rostro la mataron de perfil. Así como ahora. Ramona murió de pie y de perfil, porque no se atrevieron a asesinarla de frente". ${ }^{14}$

Al año siguiente, el periódico de las JJCC, Mundo Nuevo, resurgido a pocos días de la matanza, conmemoraba el fatídico hecho con una serie de dibujos enmarcados en viñetas que recreaban la vida, valores y virtudes de Ramona. El fin pedagógico y orientador es evidente:

RAMONA murió de pie para que nosotros no viviéramos de rodillas. Murió
como había vivido, heroica y valerosamente, murió como saben hacerlo
sólo los grandes patriotas, como lo hacen los militantes de las gloriosas
Juventudes Comunistas... RAMONA PARRA nos alumbrará el camino en la
lucha victoriosa por la liberación nacional en marcha hacia el socialismo. ${ }^{15}$

No obstante, tanto los informes periciales de balística como las declaraciones que entregó el grupo de compañeras con las que esa tarde se encontraba Ramona, realizados en el marco del sumario por los sucesos de la Plaza Bulnes, apuntan a que la muchacha buscó refugio entre el césped de la plaza. Por ejemplo, Carlota Corday Flores, de 15 años señaló que: "cuando los Carabineros empezaron a disparar, nos tendimos todas en el suelo, junto a Ramona Parra, que, al levantar un poco la cabeza, recibió una bala que le atravesó el cráneo."16 Testimonio similar entregó Mercedes Fuentes Cancino de 19 años: "No me quedó más remedio, que tirarme de bruces al pasto de los prados, lo que también hicieron varias compañeras, entre ellas, la Ramona (...) trató de incorporarse, para ver lo que ocurría, y recibió de aquellas personas, sin duda carabineros, varios balazos."17

Bien hubiesen podido acentuar la victimización resaltando la bárbara injusticia de una joven asesinada por la espalda o tendida en el suelo, pero era otra la función moral y propagandística que requería el momento político. Tal como señala Javier Varela al analizar la muerte del héroe dentro del proceso de conformación identitaria, la muerte en combate posee un carácter fundador en que opera el "rito de muerte y renacimiento". Ramona Parra pasó a ser una bandera: "el emblema vivo así publicado pretendía ilustrar el poder casi genésico de la muerte, la capacidad de los despojos de los mártires para servir de cimiento a la vida nueva de una Patria libre".18 Luego de ingresar al panteón de héroes populares' Ramona

\footnotetext{
14 El Siglo, Santiago, 29/01/ 1946, p 6

15 Mundo Nuevo, 28/01/1947 p12

16 Sumario por sucesos ... op cit $\mathrm{f} 644$

17 Ibídem

18 Javier Varela, “La muerte del héroe”. Historia Social, N¹, 1988, p22
} 


\title{
La sangre, la furia y la memoria: Ramona Parra en el martirologio comunista de la postguerra (Chile 1946-1947)
}

renacía en el colectivo enfrentando de pie a los masacradores y al destino, encarnando los atributos más altos de lo que se esperaba de una joven comunista.

Hay que agregar que la muchacha era parte de una generación de jóvenes que ingresó a militar durante la Segunda Guerra Mundial, bajo una fuerte mentalidad antifascista que se traducía en lenguajes, actitudes y se reproducía en las fricciones cotidianas que se desarrollaron en Chile. Quizás los más visibles fueron los diversos enfrentamientos callejeros entre jóvenes comunistas y nazis criollos, en cuyas escaramuzas resultó muerta la joven Eliana Miranda y la propia Ramona, fue detenida y golpeada en diversas ocasiones. Aportó a la mística militante la actuación triunfante de las tropas soviéticas en la definición del conflicto bélico. Esta generación se sentía parte del triunfo en tanto eran parte de una comunidad internacional. Así, las referencias al combate y los combatientes, la guerra, sus trincheras y necesidades serán parte de la nomenclatura cotidiana. Por ello se le otorga a la muchacha una serie de atributos que debía proyectar un combatiente ejemplar de la postguerra. Presentemos atención a una reseña de su vida elaborada por las juventudes comunistas, titulada "Dio su vida por la juventud":

\begin{abstract}
El año 1944 ingresa a las gloriosas Juventudes Comunistas para continuar así, definitivamente, el puesto que le corresponde en la lucha. Es militante esforzada, segura en la acción, lo que la hace un ejemplo de rectitud y precisión de línea. Trabaja en el Laboratorio Recalcine como obrera, y su escaso tiempo libre lo dedica a la música y a la lectura de sus autores preferidos, los teóricos del marxismo, Marx y Engels, las obras de Lenin y las enseñanzas de Stalin. ${ }^{19}$
\end{abstract}

También se reivindicará su origen humilde, proletario y deberes autoimpuestos como estudiar de noche y practicar un deporte, ejemplos de fortaleza y desarrollo integral propios de la cultura política de la era soviética. Se espera que un militante de las juventudes destile entusiasmo y una férrea voluntad, capaz de vencer cualquier prueba. Las referencias a la vida de Ramona en clave guerrillera son textuales: "Organiza con un grupo de muchachas, cursos de natación. Desea saber nadar, pues una buena guerrillera debe saberlo y una joven comunista tiene que ser una buena guerrillera". ${ }^{20}$

La inspiración comunista internacional se ensambló con experiencias propias, nacionales, que constituyeron el denso entramado que caracterizó la espesura del comunismo popular chileno, cuyos hilos complejizan cualquier análisis monolítico o dicotómico en torno a su cultura política. Es así como para el PCCH la matanza de Bulnes se inscribió en una larga tradición de lucha y matanzas obreras, que a su vez sirvieron de inspiración y ejemplo para continuar el proceso de organización, educación e intervención política.

\footnotetext{
${ }^{19}$ Mundo Nuevo, Santiago, sep 1946, p6

${ }^{20}$ Mundo Nuevo, Santiago, 28/09/1947 p12
} 


\section{Viviana Bravo Vargas}

Encontramos numerosas referencias a la sangre obrera derramada que no operaban simplemente como una metáfora, al igual que en otros episodios de esta naturaleza, los sobrevivientes, presenciaron la azarosa posibilidad de la muerte en los cuerpos de sus compañeros. La excepción aquí es que de alguna forma imperaba la idea que los tiempos de muerte a mansalva a grupos de trabajadores que demandaban derechos percibidos como legítimos, habían quedado atrás, junto con la década de 1930. Orlando Millas, por ejemplo, relata en sus memorias la estupefacción entre los organizadores y asistentes cuando comenzó el tiroteo, incluso muchos pensaron que se trataba de balas a fogueo. Tan lejos estaba del horizonte de posibilidades que le pidieron a la gente que no corriera. Pero poco después la imagen no abandonaría su memoria: "A través de la plaza había decenas de heridos. La sangre empapaba el pavimento en muchos sectores". 21

Para los presentes, la sangre que testimoniaba el azar de la muerte, de los heridos, de los sobrevivientes debía trascender y exhibirse, por ello -seguramente por una práctica que ya conocían- empaparon sus estandartes, pañuelos y carteles con la sangre de la Plaza Roja (como comenzaron a llamarle) y desfilaron por las calles céntricas de la ciudad y diversos medios de comunicación. Algunos grupos de manifestantes expresaron su furia y rompieron vitrinas, apedrearon automóviles, dieron vuelta una caseta de carabineros y otros trataron de cortar los cables de los tranvías. ${ }^{22}$ Tanta era la sangre que con la finalidad de borrar los vestigios fue limpiada en horas de la madrugada por voluntarios de la Compañía de Bomberos. No obstante, en diversas manifestaciones ocurridas en los meses siguientes los carteles ensangrentados fueron nuevamente expuestos.

Fue una imagen de alta carga simbólica que quedó gravada: "El color de la sangre es rojo, tan intensamente rojo que es imposible olvidarlo" inscribía con grandes letras la portada de Mundo Nuevo del mes de febrero de $1946 .{ }^{23}$ Pero lo más potente de la sangre derramada era que no se trataba de un hecho aislado, la individualidad del crimen trascendía en la experiencia colectiva y su larga trayectoria. Se ubicaba por tanto en un entrelazamiento de complicidades históricas que catalizaban en un elemento movilizador, anímico, propulsor. Los comunistas eran parte de una historia de sacrificios colectivos que reivindicaban con orgullo.

Una conciencia que impone deberes y marca la ruta a seguir. En este sentido, fueron diversos los discursos y textos que dirigentes y militantes hicieron llegar hasta la prensa comunista que se ubican en esta plataforma interpretativa. Por ejemplo, el poeta Andrés Sabella, integrante de la combativa Generación Literaria del 38, titulaba un conmovido texto: "Sangre del pueblo chileno en nuestras plumas". Y a continuación hacía parte de un sentimiento que alcanzaba a la militancia: "La sangre es el líquido sagrado que no se borra jamás (...) he visto las iniciales PC escritas con sangre fresca, imborrable y santa, como un tatuaje de honor por nuestra

\footnotetext{
21 Orlando Millas, En tiempos del Frente Popular, I volumen, Cesoc Ediciones, Santiago, 1993. p. 461

22 Sumario sucesos... Op Cit, fs. 309 y 675

23 Mundo Nuevo, Santiago, febrero de 1946, portada
} 


\section{La sangre, la furia y la memoria: Ramona Parra en el martirologio comunista de la postguerra (Chile 1946-1947)}

hambre por un pan luminoso en los hogares de Chile". ${ }^{24}$ Sabella emparenta esta matanza con otros sucesos históricos, entre ellos refiere a Plaza Colón de Antofagasta, Santa María de Iquique, San Gregorio, La Coruña. Y "fechas que son banderas" como el 28 y 29 de octubre de 1909 en Santiago y el 12 de mayo de 1903 en Valparaíso.

Por su parte, el novelista Nicomedes Guzmán escribió: “Homenaje a la sangre derramada, ejemplo de organización y conciencia obrera", reivindicando la memoria histórica hacia la consecución de luchas futuras. Un proyecto que se sostiene en el diálogo entre tiempos pretéritos y futuros:

Así, la sangre derramada en los trágicos minutos del lunes pasado, a instancias inconscientes de un grupo de hombres armados -pero DESALMADOS-, ha venido a revivir en los corazones de todo el pueblo chileno una tradición que es el orgullo de una clase y constituye el alma en el proceso de las conquistas sociales de esta aporreada y aguerrida tierra. ${ }^{25}$

A un año de los sucesos, El Siglo dedicó una edición especial con poemas, grabados, fotografías y columnas de opinión que reforzaban esta idea: "Porque solo la sangre florece en el estéril cemento, nació ahí, hace hoy un año, la verdadera unidad obrera. La forjada en el sacrificio." 26

\section{Renacer en el colectivo: "Ramona nos marca el camino"}

Las ideas-fuerzas que hemos analizado se expresan claramente a través de diversas iniciativas movilizadoras que impulsó el PCCH para homenajear a los caídos, como el propio funeral de las víctimas. En diversas fotografías publicadas en la prensa nacional puede observarse a las viudas rodeadas de sus hijos en luto riguroso y cuantiosos arreglos florales hechos llegar hasta el local de la CTCH donde fueron velados. Una larga fila de hombres, mujeres y niños observa la conmovedora escena mientras esperan su turno para acercarse a los féretros.

A la mañana siguiente, un disciplinado contingente de jóvenes en bicicleta abrió paso entre aproximadamente doscientas mil personas al cortejo fúnebre que lentamente circuló en su marcha hasta el Cementerio General. Precediendo a los ataúdes marchaban guardias de honor enarbolando las banderas partidarias y organizaciones sindicales. Las crónicas se detienen en el fuerte sol de fines de enero, por ello se reportaron diversos casos de mareo y desmayos, que fueron mitigados por el apoyo de voluntarios de la Defensa Civil. Los organizadores solicitaron que no hubiese fuerza pública, y a ello adjudicaron más tarde que las exequias se desarrollaran en completo orden y tranquilidad.

\footnotetext{
${ }^{24}$ El Siglo, Santiago, 30/01/1946, p 2

${ }^{25}$ El Siglo, Santiago, 31/01/1946, portada 2do cuerpo

${ }^{26}$ El Siglo, Santiago, 28/01/1947, p 11
} 


\section{Viviana Bravo Vargas}

El contexto en que se producen las exequias es fundamental destacarlo. Más de un $\mathbf{8 0 \%}$ de la ciudad de Santiago adhería al Paro Nacional dándole un carácter aún más solemne y confrontacional a la despedida. El diario El Siglo anunciaba en primera página: “Chile no va hoy a la fábrica. Va al cementerio a acompañar en una columna interminable, como el destino del pueblo, a esa sangre de su sangre caudalosa derramada en un crimen sin nombre"27. Muchos de los trabajadores junto a los estandartes de sus organizaciones acompañaron los restos cubiertos por las banderas del Partido Comunista, Socialista y las Juventudes Comunistas, hasta el mausoleo del Sindicato Cristalerías de Chile, donde representantes de fuerzas políticas, estudiantiles, sindicales expresaron su indignación y apoyo al petitorio presentado ante las autoridades. Continuaba así, entre otros puntos considerados como apremiantes, la exigencia de reintegrar la personalidad jurídica a las oficinas salitreras en conflicto, y la preocupación concreta ante la llegada de uniformados al gabinete. También abordaba un punto que el PCCH no abandonará en este período: la investigación de los hechos, el castigo a los responsables e indemnización a los familiares de los muertos y heridos en la plaza. ${ }^{28}$

Hasta entonces el PCCH tenía la expectativa de encontrar respuestas favorables y ser solicitado para la conformación de un gobierno civil progresista que atendiera las demandas obreras. La prueba de fuerza que dio el exitoso paro nacional y la movilización de sectores populares parecían respaldar la tesis. Pero a los pocos días el cuadro político se complejizaría aún más con la fractura de la CTCH debido a la incorporación del Partido Socialista al gobierno de Alfredo Duhalde con tres importantes carteras ministeriales y la "bajada" de este sector del nuevo paro nacional consensuado para el 4 de febrero. ${ }^{29}$

La tensa relación comunista-socialista que ambos partidos venían maniobrando durante varios años, terminaba por hacerse trisas. Acusando un complot soviético en el país, la sección de la CTCH hegemonizada por el comunista Bernardo Araya, mayoritaria por cierto, fue desconocida por el gobierno, y desalojada de la sede sindical, además de enfrentar varias formas de hostigamiento que afectaron a organizaciones sindicales. Hasta el verano de 1946 los socialistas parecían ubicarse en posiciones favorables, la CTCH de Bernardo Ibáñez gozaba de influencia al interior del gobierno y ajustaba cuentas con su contendor.

En este cuadro Ramona fue una bandera de lucha presente en diversos actos que continuaron celebrándose las semanas y meses siguientes. Por ejemplo, el domingo 17 de marzo las JJ.CC realizaron un cálido homenaje a la mártir de la juventud chilena en el que expresaban: "Nuestra compañera RAMONA PARRA, caída bajo el fuego asesino en la tarde sangrienta del 28 de enero". El lugar elegido fue el Sindicato de CHILECTRA, cuyos trabajadores continuaban en paro de actividades debido al estancamiento en las negociaciones. Como muestra solidaria se solicitaba

${ }^{27}$ El Siglo, Santiago, 30/01/ 1946, p. 8

${ }^{28}$ El petitorio de la CTCH se reproduce detalladamente en: Crisóstomo Pizarro, La huelga obrera en Chile, Santiago, SUR, 1986

${ }^{29}$ Sobre el quiebre de la CTCH ver Cristian Pozo, Ocaso de la unidad obrera... Op Cit 


\section{La sangre, la furia y la memoria: Ramona Parra en el martirologio comunista de la postguerra (Chile 1946-1947)}

a los asistentes aportar con un tarro de leche o un kilo de alimentos para ayudar a los huelguistas, y se anunciaba como atractivo de la jornada la proyección del film soviético antifascista "El profesor Mamlock", muy recepcionado en aquellos años. ${ }^{30}$

Además del florecimiento de este tipo de actividades hay una operación de reintegrar simbólicamente a Ramona al partido. No sólo se trata de mantenerla presente gracias a operaciones mnemotécnicas, sino que a través del proceso de "emular, recordar y renacer" que observamos en la intensa campaña de reclutamiento.

Ciertamente que desde antes de la matanza el PCCH aumentaba su influencia en la sociedad chilena con la incorporación de intelectuales, trabajadores y estudiantes. Este crecimiento se evidenció en la hegemonía que alcanzó en las directivas del cobre, salitre y carbón, que eventualmente le permitía paralizar las fuentes productoras del 70\% o más de las divisas que Chile necesitaba, y elementos estratégicos para la industria y el transporte ${ }^{31}$; además de tener una representación parlamentaria de quince escaños. No obstante, después del 28 de enero, la campaña de reclutamiento cobró nuevos bríos.

El Comité Central de las JJCC dio orientaciones para difundir y promover el ingreso a la llamada Promoción Ramona Parra. La muchacha renacería en una generación con vientos redentores, dispuesta a enfrentar los desafíos urgentes que imponía el momento político. Si bien las aspiraciones cuantitativas eran innegables, los criterios de selección debían ser prioritarios. Se insistía: "Debemos captar para nuestra organización a los jóvenes más combativos". ${ }^{32}$ En dicha tarea el periódico de la Juventudes Comunistas, Mundo Nuevo, cumplió un importante papel. El primer ejemplar era vehemente: "Joven chileno, exhibe el orgullo de ingresar en nuestras filas en la "PROMOCIÓN RAMONA PARRA"... BAJO LA BANDERA DE RAMONA PARRA Y EN LAS FILAS DE LA JUVENTUD COMUNISTA, LUCHAREMOS POR LA LIBERTAD DE NUESTRA PATRIA".33

No sólo se trataba de sumarse al proyecto político de Ramona sino que recaía la responsabilidad de ocupar su lugar. Por ello, dos semanas más tarde, junto con saludar a los nuevos militantes que se incorporaban (35 en San Miguel, 10 en la Novena Comuna, 9 en la Sexta Comuna, y 12 en la Séptima) se insistía en esto dentro de un ritual de iniciación: "vienen a ocupar el puesto dejado por nuestra querida Ramona Parra. Nuestros nuevos afiliados serán recibidos en el gran acto de homenaje a Ramona Parra que se realizará el 8 de marzo". ${ }^{34}$

La portada del tercer ejemplar de Mundo Nuevo exhibió un dibujo inspirado en la estética del artista plástico José Venturelli. En él se observa una mujer caída sobre una alfombra roja que podría ser su propia sangre, más atrás, un grupo de

\footnotetext{
30 Mundo Nuevo, 3era semana de marzo 1946, portada

${ }^{31}$ Huneeus, La Guerra fría... op cit, p 77

32 "Realicemos una gran conferencia nacional de Juventudes Comunistas de Chile" 15, 16 y 17 de noviembre de 1946, p $6 y 7$

33 Mundo Nuevo, Santiago, febrero 1946, p 4

34 Mundo Nuevo, Santiago, 16/02/1946,p 2
} 


\section{Viviana Bravo Vargas}

jóvenes observa la escena con el puño en alto, bajo una gran pancarta de las juventudes comunistas. Se insiste: "Promoción Ramona Parra. En las filas de las Juventudes Comunistas a luchar por los derechos de los jóvenes... enarbolando como gloriosa enseña el nombre de nuestra querida Ramona Parra, abre sus puertas para ofrecer a todos los jóvenes chilenos un puesto junto a nosotros para forjar con nuestra lucha un porvenir seguro y alegre para la joven generación". ${ }^{35}$ Ya en el mes de marzo se anunciaba con regocijo el éxito de la campaña en regiones. Sólo en Concepción ingresaban 230 jóvenes, ${ }^{36}$ en tanto en la cuarta comuna de Valparaíso, se tributaba su legado y simbolizaba el renacimiento a través de la conformación de una base con su nombre. ${ }^{37}$

Además de apoyar el proceso de movilización, la generación Ramona Parra se incorporó en tareas apremiantes para las JJCC, tanto en las labores de apoyo y solidaridad con los huelguistas, como en el trabajo territorial contra la especulación y el alza de los productos de consumo básico a través de los Comités de Subsistencia, en la formación de brigadas para recorrer los centros de ocultamiento de mercancías y vigilancia contra los acaparadores ${ }^{38}$. Paralelamente, después del 20 de julio y el apoyo del partido a la candidatura presidencial del militante del Partido Radical Gabriel González Videla, las JJCC protagonizaron un intenso trabajo de campaña electoral, recorrieron el país explicando el programa de gobierno emanado de la Convención de Partidos y Organizaciones Democráticas y organizaron comités juveniles provinciales de carácter multisectorial. Más tarde, reivindicarán su trabajo, como motor del triunfo electoral.

\section{A un año de la masacre: "el mejor homenaje es el cumplimiento del programa"}

El 4 de septiembre de 1946, González Videla ganó estrechamente las elecciones con Pablo Neruda como jefe de campaña. Pero el trabajo no bajó de intensidad. El candidato alcanzó la primer mayoría relativa con el 40.1\% de los sufragios, por lo que la elección quedó en suspenso hasta su ratificación por el congreso. Diversos sectores se declararon en estado de alerta ante una posible arremetida de la derecha. Fue un período de marchas, comicios, asambleas y diversas manifestaciones populares. La CTCH comandada por el comunista Bernardo Araya convocó a un paro nacional el 24 de octubre, día en que el parlamento debía pronunciarse. Por su parte las JJCC, alentaron una actitud más combativa y advertían: "El triunfo obtenido con tanto sacrificio está en peligro", y muy en la tónica del imaginario antifascista llamó a conformar milicias populares, aunque no tenemos antecedentes sobre su concreción: "Deben ser de una gran

\footnotetext{
35 Mundo Nuevo, Santiago, 3aㅗ semana de febrero 1946, portada

36 Mundo Nuevo, Santiago, 3a semana de marzo 1946, p.4

37 Mundo Nuevo, Santiago, 2ª semana de abril 1946, p.4

38 "Conferencia Nacional de las Juventudes Comunistas", Santiago 15, 16 y 17 de noviembre 1946, p 4
} 


\section{La sangre, la furia y la memoria: Ramona Parra en el martirologio comunista de la postguerra (Chile 1946-1947)}

amplitud, compuestas por jóvenes democráticos de todos los sectores sociales y con distintivos simples y fáciles de adquirir por toda la juventud. Las milicias populares serán la mejor garantía del régimen democrático y de las libertades públicas, contando en estas tareas con la ayuda de las fuerzas armadas, que son parte de nuestro pueblo." 39

Después del intenso despliegue de fuerza orgánica, la consagración del triunfo marcó un parteaguas para el PCCH. Fue experimentado como una batalla ganada a la cual habían aportado decisivamente. Entre el 28 de enero y el 4 de septiembre se trazó un arco de tiempo cómplice, de aliento movilizador, esto se confirma en las Conferencias Nacionales del PCCH y de las JJCC, realizadas entre octubre y noviembre respectivamente, a la hora de evaluar el triunfo: "Fue la culminación de todo un período de luchas que se hizo más intenso especialmente después de la masacre del 28 de enero" 40 . En esta misma línea se pronunciaban las Juventudes Comunistas: "Desde el 28 de enero, el proletariado chileno, con entusiasmo y combatividad crecientes, ha comenzado a desempeñar su papel de vanguardia bajo la dirección política del Partido Comunista, proceso que se acelera cada día más". 41

Las expectativas eran muchas. Por primera vez tres comunistas ocuparon posiciones ministeriales: Víctor Contreras Labarca como Ministro de Obras Públicas; Miguel Concha Quezada en Agricultura y Víctor Contreras Tapia en Tierras y Colonización. Además de cinco intendencias, entre ellas Tarapacá y Santiago. Dicha participación, además de su representación parlamentaria, les permitió solicitar la inscripción legal como partido político. Recordemos que hasta entonces el PCCH era considerado una asociación ilícita, debiendo inscribir a sus candidatos en listas de otros partidos o idear la denominación de Partido Democrático Nacional primero que también sería cancelada en 1941- o como Partido Progresista Nacional más tarde. Solicitud que finalmente obtuvo en enero de 1947. Además, en la práctica el gobierno ya había otorgado reconocimiento como principal interlocutora a la CTCHAraya.

No obstante, existían elementos adversos en la coyuntura política. La ratificación de González Videla por el senado había estado condicionada al apoyo del Partido Liberal, que como condición exigió la participación en el gabinete con igual número de ministros que los comunistas y -lo que será el tema más conflictivo- la suspensión de la legislación para concretar la sindicalización campesina, prometida en el programa de gobierno. ${ }^{42}$ Además en los albores de la Guerra Fría la campaña anticomunista ya se expresaba en diversas tendencias políticas, incluso dentro del propio Partido Radical.

\footnotetext{
39 "Realicemos una gran conferencia... Op. Cit. p.5

40 Ricardo Fonseca, "Defensa del triunfo y cumplimiento del programa!" Conferencia Nacional del

Partido Comunista. Octubre de 1946. p 25

41 "Realicemos una gran conferencia...", Íbidem

42 Huneeus, La Guerra Fría... Op. Cit. p 89
} 


\section{Viviana Bravo Vargas}

Pero a pesar de estas tendencias, el PCCH continuaba sumando adeptos y la campaña de reclutamiento se evaluaba exitosamente con la incorporación de tres mil militantes. En tanto se anunciaba una segunda etapa de la Promoción Ramona Parra que se extendería hasta el 1ero de mayo de 1947.43 La meta era captar 30 mil militantes. Reforzando los factores subjetivos que conducían a valientes y abnegados jóvenes a la lucha, la Conferencia Nacional de las JJCC dedicó un destacado espacio a la memoria de "Ramona Parra, guía y ejemplo para la juventud chilena", donde se destacan cualidades que hemos referido: "Su vida es un continuado ejemplo de firmeza revolucionaria, de cariño a las Juventudes Comunistas, de afán de superación, de fe ilimitada en las fuerzas de la juventud obrera y adhesión a la noble causa del Socialismo". La muchacha era heredera de O’Higgins, Manuel Rodríguez y Recabarren, además de procesos populares que culminaron en matanzas obreras, pero, "en primer término, ella conocía y admiraba las proezas de los heroicos jóvenes soviéticos que con empuje indomable han ido construyendo una nueva sociedad." 44

Y a continuación, se evidencia la temprana tensión que el PCCH mantendrá con la administración de González Videla respecto a la masacre: "La juventud no puede aceptar que a diez días de la constitución del actual gobierno todavía permanezca impune el crimen de la Plaza Bulnes"45. Misma postura expresará respecto a la reorganización del campo y sindicalización campesina, cuestión definida como prioritaria tanto en el congreso nacional de la CTCH-Araya (diciembre 1946) como en las conferencias nacionales comunistas. En este sentido, utilizando el nuevo anclaje ministerial y la inserción territorial de sus militantes, impulsaron una campaña de denuncia contra el abuso de latifundistas y fomentaron el proceso de organización rural con sus principales focos en Santiago, Talca, Curicó y Linares. La derecha acusó el golpe y exigió controlar la labor agitativa del PCCH en el campo a la que adjudicaron los diversos conflictos suscitados en el verano de 1947.46 Algunos de sus titulares eran elocuentes: "Agricultores de zona de Teno y Curicó piden garantías al Presidente de la República contra agitación comunista"47; "Agitador comunista extraño a fundo de cañete, encabeza huelga abiertamente ilegal" 48

Y es que si bien el PCCH se comprometía a cooperar con el gobierno, desde un inicio marcó su raya dentro de una táctica política que Carlos Huneeus ha definido "de dos caras"49, actuando dentro y fuera del gobierno, lo que complicó e irritó al presidente. Efectivamente, si González Videla esperaba neutralizar las protestas con el ingreso del PCCH al gobierno, la realidad se manifestaba distinta.

\footnotetext{
43 "Realicemos una gran conferencia... Op Cit, pp $6 y 7$

44 "Tercera Conferencia Nacional de las JJ.CC. Informe del Secretario General Daniel Palma 1947", p.4

45 Ibídem

46 Ver por ejemplo El Diario Ilustrado, de tendencia conservadora entre enero y febrero de 1947.

47 El Diario Ilustrado, Santiago, 24 de enero de 1947, p.1

48 El Diario Ilustrado, Santiago, 2 de febrero de 1947, p.1

${ }^{49}$ Huneeus, La Guerra Fría... Op Cit. p.38
} 


\section{La sangre, la furia y la memoria: Ramona Parra en el martirologio comunista de la postguerra (Chile 1946-1947)}

Aún más al interior de las bases. Por ejemplo, como ha detallado la historiadora Jody Pavilack, los mineros del carbón aclararon en una carta dirigida al presidente que si bien habían respaldado su candidatura su apoyo no era incondicional: "no sería dado a expensas de sus propios intereses, sin importar los compromisos hechos por sus líderes nacionales" ${ }^{\prime \prime}$.

No sería el único campo en disputa. En enero de 1947 hubo conflictos locales derivados del alza de los alimentos y de las tarifas de electricidad, y ya se rumoreaba el alza del transporte público. Además del proceso inflacionario se denunciaban los abusos patronales en las condiciones del trabajo (intensificación) y de los especuladores contra el consumo popular (producción y consumo) ${ }^{51}$. El malestar general se expresó en un intenso despliegue mediático y callejero que los comunistas, a la vez que eran parte, esperaban resolver exigiendo que el gobierno cumpliese la palabra empeñada. Incluso, tiempo antes, el PCCH hizo llegar al ejecutivo un documento en que resumió las medidas más urgentes a implementar en conformidad al programa como la reorganización del comisariato para asegurar un efectivo control de precios, de la especulación y abastecimiento de productos de primera necesidad; y de vivienda como la prohibición de los llamados lanzamientos o desalojos de viviendas populares, control y tope máximo de las rentas y construcción de diez mil viviendas de emergencia. ${ }^{52}$

En este marco, el aniversario de la masacre del 28 de enero sirvió para aglutinar los esfuerzos, movilizar el descontento y demostrar mayor en el espacio público. Observamos en los preparativos y concreción de este gran homenaje, como la memoria y ceremonialización de la muerte opera para potenciar demandas y desafirs que plantea el presente.

Semanas antes la CTCH-Araya llamó a todas sus instancias a organizar actos preparativos, especificando que "deben tener el carácter de homenaje a nuestros muertos del 28 de enero del año pasado; y de movimiento de masas para acelerar el cumplimiento del programa y afianzar el régimen, amenazado por los reaccionarios incrustados en el Gobierno". ${ }^{33}$ A nivel local las iniciativas fueron patrocinadas por los Comités de Subsistencias, que solicitaban el fin al encarecimiento de los arriendos y art这ulos de primera necesidad. Por ejemplo, en las poblaciones Recreo y Colón de San Miguel se celebró un mitin con el propósito de "protestar por la acción de los especuladores y movilizar a todos los sectores populares al acto del 28 en la plaza Bulnes". Desde mediados de enero se registraron concentraciones de este tenor en San Pablo esquina Manuel Rodr guez, Av. México con Recoleta, en Pedro Lagos con Nataniel. ${ }^{54}$ En la Plaza Manuel Rodr fyuez de Puente Alto, en el Teatro del pueblo de Quilicura, en calle Colombia esquina El Salto de Conchal?̂̉y un comicio relámpago en Plaza Bogotá.

\footnotetext{
50 Pavilack, Mining for the... Op Cit. p161

51 Pozo, Ocaso de la unidad... Op. Cit.

52 Ricardo Fonseca, "Plan inmediato de gobierno del Partido Comunista", Santiago, 1946

53 El Siglo, Santiago, 25/01/1947 p 5

${ }^{54}$ El Siglo, Santiago, 24/01/1947, p.5
} 


\section{Viviana Bravo Vargas}

En Rancagua hubo un desfile desde la Estación hasta la Plaza de los Héroes. En tanto la Central Nacional de Defensa de los Consumidores, organizó un acto en la Plaza Artesanos para exigir la reorganización del comisariato, posteriormente desfilaron hasta Plaza Vicuña Mackenna para converger en el acto organizado por el Movimiento pro-Emancipación de la Mujeres Chilenas, donde dos mil personas se manifestaban en contra el reciente fallo de la Contralor de la República que prohibió a mujeres ocupar cargos públicos, afectando entre ellas a la dirigente comunista Mar通 Marchant inicialmente propuesta para Intendente de Santiago. ${ }^{55}$ Las JJCC de Coronel rindieron un homenaje a Ramona Parra en el teatro de los obreros de Schwager, también en esta ocasión se insist媃: "se pedirá el cumplimiento del programa, el abaratamiento de la vida y se analizará la necesidad de mantenerse alerta y en continua movilización para desbaratar los negros designios de los complotadores" 56 .

En la tarde del martes 28 de enero de 1947 cuatro columnas desfilaron desde puntos neurálgicos de Santiago: Plaza Baquedano, Estación Central, Avenida Matta con Arturo Prat y Plaza Artesanos, para converger en Plaza Bulnes. ${ }^{57}$ En tanto, una columna agrupada bajo el estandarte "sobrevivientes" hizo su propio recorrido y fue ovacionada al llegar a la plaza. Con el primer toque de silencio se dio paso al acto artístico. Una descarga al aire simbolizando la masacre y al calor de los temas evocados por el coro popular que ensayó desde semanas anteriores, se simuló una gran mancha de sangre arrojando las flores rojas, que previamente se les solicitó portar a los asistentes. Posteriormente las directivas de los organismos pol团icos y sindicales a las que pertenecieron las v隹timas colocaron arreglos florales en los que se inscribió el nombre de los ca唄os con flores blancas.

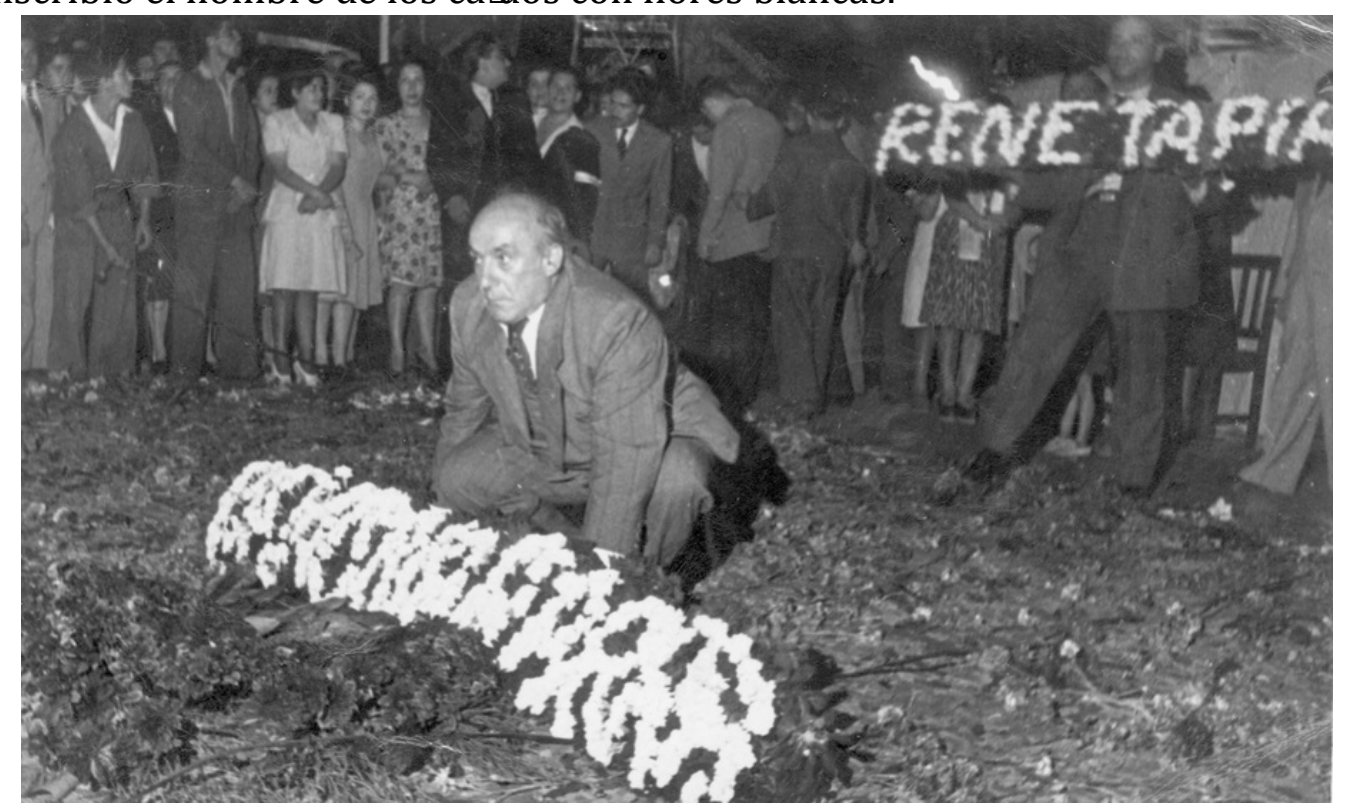

Foto $\mathrm{N}^{\circ} 1$ El通s Lafertte, Secretario General del PCCH, deposita ofrenda en honor a Ramona Parra. Disponible en: https://commons.wikimedia.org/w/index.php?curid=30353387[Consulta: 03/06/2017].

${ }^{55}$ El Siglo, Santiago, $25 / 01 / 1947$, portada

${ }^{56}$ El Siglo, Santiago, 25 /01/1947 p 5

${ }^{57}$ El Siglo, Santiago, 24 /01/1947, portada 


\title{
La sangre, la furia y la memoria: Ramona Parra en el martirologio comunista de la postguerra (Chile 1946-1947)
}

Entonces resonó la voz del poeta Pablo Neruda: "yo no vengo a llorar aquí donde cayeron". Se trataba del poema "Los muertos de la plaza", que inmortalizaría en el Canto General, donde relaciona la masacre con muertes anteriores pero también en las necesidades presentes. Estas ideas fueron condensadas en el verso a Ramona:

\author{
Ramona Parra, joven \\ Estrella iluminada \\ Ramona Parra, frágil heroína \\ Ramona Parra, flor ensangrentada \\ Amiga nuestra, corazón valiente \\ Niña ejemplar, guerrillera dorada: \\ Juramos en tu nombre continuar esta lucha \\ Para que asíflorezca tu sangre derramada.
}

La ocasión también sirvió para generar recursos. El PCCH editó treinta mil ejemplares de un álbum con el poema de Neruda e ilustrado con dibujos de José Venturelli: "íntegramente confeccionado a base de dibujos que dicen relación con los luctuosos hechos de Plaza Bulnes, los que serán vendidos a \$10 el ejemplar. Una tirada de trescientos ejemplares con firma de los distinguidos artistas será vendido a $\$ 50$ ejemplar". 58

Con el segundo toque de silencio se dio comienzo al acto político. Destacadas personalidades hablaron desde un escenario en el que se esperó en algún minuto que se encontrara González Videla. El núcleo de lo planteado en que todos los oradores coincidieron podría resumirse en las palabras de Ricardo Silva, presidente provincial del movimiento falangista: "el mejor homenaje que podemos rendir a los muertos el 28 de enero, es el cumplimiento del Programa".59

En este sentido es interesante el discurso pronunciado por el abogado comunista René Frías Ojeda, regidor por Santiago, que tuvo a cargo la defensa de las víctimas. Frías en diversas tonalidades y varias partes de su intervención recordó al presidente que era deudor del pueblo y su programa: "permanecen vivas en el aire de esta Plaza Roja las palabras pronunciadas por el militante de ese partido señor Gabriel González Videla, cuando como presidente electo dijo: Jamás daré la espalda al pueblo, cumpliré el programa; al pueblo le debo todo lo que soy" 60 e insistía: "en esta Plaza se congrega ahora el pueblo a fin de recoger fuerzas junto al recuerdo de sus hechos heroicos, para marchar adelante hacia la realización de su destino; el programa del 4 de septiembre" 61

La portada de El Siglo con que se informó el homenaje también era decidor de las ideas que movilizaba el PCCH: "Cumplimiento del programa. Chile entero lo pidió ayer". Y a continuación:

\footnotetext{
${ }^{58}$ El Siglo, Santiago, 23/01/1947, p5

${ }^{59}$ El Siglo, Santiago, 29/01/1947, portada

${ }^{60}$ El Siglo, Santiago, 29/01/1947, portada

${ }^{61}$ El Siglo, Santiago, 29/01/1947, portada
} 


\section{Viviana Bravo Vargas}

Junto a las flores rojas que portaban los obreros y las dueñas de casa para depositar en el lugar preciso en que fue asesinado cada uno de los seis mártires, se alzaban los letreros en lienzos y cartones escritos por manos de trabajadores y que gritaban en negros caracteres lo que el pueblo pide, lo que el pueblo quiere del Gobierno... RAPIDO CUMPLIMIENTO DEL PROGRAMA. ${ }^{62}$

En el Congreso de la República el 28 de enero, en tanto fecha-monumento también cambió el curso del tiempo burocrático. Para conmemorarlo los personeros comunistas tomaron la palabra para rendir homenaje. El diputado Andrés Escobar, sobreviviente de la Plaza Bulnes, no perdió la ocasión para exigir justicia y recordar la deuda suscrita por González Videla: "sin la abnegación y el heroísmo de que las masas dieron tantas pruebas desde la tarde sangrienta del 28 de enero, no se habrían creado las condiciones políticas ni objetivas para el triunfo del 4 de septiembre, ni se habría conseguido la firmeza para defender la victoria y exaltar al poder al candidato triunfante."63

Después de este homenaje el PCCH continuó movilizado en razón de las próximas elecciones municipales, para lo cual se había propuesto crecer exponencialmente. Así el 6 de abril de 1947 el PCCH -que por primera vez participaba con su nombre real en las elecciones- triplicaba su votación pasando de 32 mil votos en 1944 a 91 mil, y porcentajes por sobre el 50\% en las conflictivas zonas del cobre, salitre y carbón. ${ }^{64}$ No obstante, este proceso de crecimiento y movilización fue frenado insospechadamente.

Pocos días más tarde comenzó la cruzada en contra del comunismo. Como primer paso, González Videla consiguió la renuncia de los ministros del PCCH acusados de propiciar "una ola de huelgas". Entre fines de agosto de 1947 y enero de 1948, con los votos de parlamentarios radicales, liberales y conservadores, obtuvo facultades extraordinarias que entre otras prerrogativas le permitieron aprehender a individuos sin orden judicial y relegarlos a lugares apartados del país. Argumentando que el peligro comunista no se había neutralizado, en septiembre de 1948 fue promulgado el proyecto de Ley de Defensa Permanente de la Democracia, conocido como "ley Maldita". En razón de ella, al cabo de cien días se eliminó aproximadamente 30 mil votantes comunistas, hubo numerosas purgas en el movimiento sindical y diversos dispositivos de espionaje y castigo.

\section{Conclusiones}

El martirologio comunista de la postguerra ensambló la aureola de víctima con la virtud del héroe. En este sentido, la interpretación que hizo el PCCH no sólo se detuvo en el hecho traumático, sino que éste era resignificado e incluso

\footnotetext{
${ }^{62}$ El Siglo, Santiago, 29/01/1947, p 3

${ }^{63}$ El Siglo, Santiago, 29/01/1947, p 2

${ }^{64}$ Huneeus, La Guerra Fría... Op. Cit. pp 109-112
} 


\section{La sangre, la furia y la memoria: Ramona Parra en el martirologio comunista de la postguerra (Chile 1946-1947)}

maniobrado con el fin de servir de elemento propulsor para enfrentar los desafíos imperantes. Las víctimas de la Plaza Bulnes no eran entes pasivos, por el contrario, se les atribuyó una capacidad de agencia que insistió (e incluso exageró) en su perfil combativo. Ser agente significa conciencia, voluntad, decisión. Así una manifestación pacífica y autorizada pasó a ocupar un sitial en las diversas batallas de un proceso largo que se encadena hacia atrás y hacia adelante. Insertarlo en una historia y en una continuidad de sacrificios lo eximió de la singularidad, en cuanto no se trataba de un hecho aislado (la memoria de lo puntual que deriva en la sacralización del hecho) sino que en una generalidad inscrita en un pasado compartido y una voluntad común en el presente.

Si bien durante el extenso tiempo en que operó la proscripción del PCCH, el 28 de enero de 1946 como fecha-monumento no fue nuevamente reivindicado, al menos públicamente, Ramona Parra continuó siendo una bandera de lucha. Así, a raíz de las necesidades de la contienda política, en 1968 cuando en el VI Congreso de las JJCC concretó la idea de conformar destacamentos de propaganda que intervinieran los muros las llamó Brigadas Ramona Parra (BRP).

La primera aparición pública de la BRP fue durante la marcha en solidaridad con Vietnam realizada desde Valparaíso a Santiago en septiembre de 1969. Desde entonces las BRP fueron adquiriendo masividad y protagonismo, transformándose en un referente estético al que el nombre de la muchacha quedó indisolublemente ligado. Poco después, en pleno proceso de la Unidad Popular, en un reportaje dedicado a la brigada titulado "Ramona Parra, recuerdo que le pena a los momios", los muchachos se definían tributarios de una joven heroína obrera capaz de realizar hazañas ejemplares en el largo camino de combate del pueblo. Y entregaban la versión que escucharon y seguramente reelaboraron sobre su muerte: "Ramona Parra fue agredida por un oficial que, de un manotazo la arrojó al suelo. La muchacha se levantó, arrancó una mata de pasto y se la metió en la boca a su agresor. Enfurecido, éste saco su revólver y le destrozó la cabeza de dos balazos."65

Ramona también fue el nombre de la revista que al calor del mismo proceso crearon las Juventudes Comunistas66. Ciertamente eran otros jóvenes, con sus propios tiempos y urgencias, pero sus razones y sentimientos se enlazaban a un proceso de lucha histórica del cual se sentían parte y que reivindicaban con orgullo.

\section{Bibliografía}

Álvarez, Rolando, Arriba los pobres del mundo, Santiago, LOM, 2011

\footnotetext{
65 Ahora, Santiago, diciembre 1971, p.24-25

66 Ver: Carolina Fernández Niño, “Revista Ramona 1971-1973”. En: Rolando Álvarez; Manuel Loyola (editores) Un trébol de cuatro hojas. Las juventudes Comunistas de Chile en el Siglo XX. AriadnaAmérica en Movimiento, Santiago, 2014
} 


\section{Viviana Bravo Vargas}

Barnard, Andrew, The Chilean Communist Party: 1922-1947. Ph.D thesis, University of London, 1977

Bravo Vargas, Viviana, Con la razón y la fuerza venceremos! la rebelión popular y la subjetividad comunista en los '80, Santiago, Ariadna, 2010

Bravo Vargas, Viviana, "Chile no va hoy a la fábrica: Protesta obrera y represión política en el verano de 1946", Izquierdas 35, septiembre 2017, pp. 199-232

Fernández Niño, Carolina, "Revista Ramona 1971-1973". En: Rolando Álvarez; Manuel Loyola (editores) Un trébol de cuatro hojas. Las juventudes Comunistas de Chile en el Siglo XX. Santiago, Ariadna-América en Movimiento, 2014

Grez, Sergio, Historia del comunismo en Chile. Los tiempos de Recabarren (19121924), Santiago, LOM, 2011

Huneuus, Carlos, La Guerra Fría Chilena. Gabriel González Videla y La Ley Maldita. Santiago, Debate, 2009

Melgar Bao, Ricardo, "Muerte, martirologio y mitología del renacer en las guerrillas latinoamericanas". En: La memoria sumergida, 2002. Disponible en: http://www.cedema.org/uploads/La\%20memoria\%20sumergida.pdf

Melgar Bao, Ricardo, "Una cultura política en formación: los cominternistas centroamericanos". En: Elvira Concheiro, Massimo Modonesi, Horacio Crespo (coord), El comunismo: otras miradas desde América Latina, México, CEIICH-UNAM, 2007

Millas, Orlando, En tiempos del Frente Popular, I volumen, Santiago, Cesoc Ediciones, 1993

Pavilack, Jody. Mining for the Nation. The Politics of Chile's Coal Communities from the Popular front to the Cold War. University Park: The Pennsylvania State University Press, 2011.

Pinto, Julio, Luis Emilio Recabarren. Un biografía histórica, Santiago, LOM, 2013.

Pizarro, Crisóstomo, La huelga obrera en Chile, Santiago, SUR, 1986

Pozo Mayorga, Cristian, Ocaso de la unidad obrera en Chile: confrontación comunistasocialista y la división de la CTCH (1946-1947). Tesis de Magíster, Santiago, Universidad de Chile, 2013.

Ramírez, Hernán, Origen y formación del Partido Comunista de Chile, Santiago, Progreso, 1984

Renan, Ernest ¿Qué es una Nación? Conferencia dictada en la Sorbona, París, 11 de marzo de 1982.1 Disponible en: http://enp4.unam.mx/amc/libro munioz cota/libro/cap4/lec01 renanqueesunan acion.pdf. 


\section{La sangre, la furia y la memoria: Ramona Parra en el martirologio comunista de la postguerra (Chile 1946-1947)}

Rojas, Luis, De la rebelión popular a la sublevación imaginada, Santiago, LOM, 2011

Salgado, Alfonso, "La familia de Ramona Parra en la Plaza Bulnes: Una aproximación de género a la militancia política, la protesta social y la violencia estatal en el Chile del siglo". Izquierdas 18, IDEA-USACH, Santiago de Chile, abril 2014, pp. 128-145

Varela, Javier "La muerte del héroe". Historia Social N¹, primavera-verano,1988, pp. 19-28

Williams, Rymond, Marxismo y literatura. Buenos Aires, Las Cuarenta, 2009.

\section{Documentos del Partido Comunista Chileno}

Realicemos una gran Conferencia Nacional de Juventudes Comunistas de Chile" 15, 16 y 17 de noviembre de 1946.

Conferencia Nacional de las Juventudes Comunistas, Santiago 15, 16 y 17 de noviembre 1946

Fonseca, Ricardo, “ ¿Defensa del triunfo y cumplimiento del programa!” Conferencia Nacional del Partido Comunista. Octubre de 1946.

Fonseca, Ricardo, "Plan inmediato de gobierno del Partido Comunista”, 1946

Tercera Conferencia Nacional de las JJ.CC. Informe del Secretario General Daniel Palma, 1947

Recibido: $17 / 06 / 2017$

Evaluado: $27 / 07 / 2017$

Versión Final: 26/08/2017 